\title{
Graham-Little Piccardi Lassueur Syndrome and review of the literature
}

\author{
fares alkhayal ${ }^{1}$, Fahad Alsudairy ${ }^{1}$, luluah al Mubarak ${ }^{1}$, and Hind M. Almohanna ${ }^{1}$ \\ ${ }^{1}$ Prince Sultan Military Medical City
}

July 12, 2021

\begin{abstract}
Graham-Little Piccardi Lassueur Syndrome (GLPLS) is a rare variant of Lichen planopilaris (LPP) which characterized by triad of fibrosing alopecia of the scalp, non-fibrosing alopecia of the axilla and groin, and a follicular spinous papule over the body.
\end{abstract}

Graham-Little Piccardi Lassueur Syndrome and review of the literature

Fares A. Alkhayal, Fahad Alsudairy, luluah al Mubarak and Hind M. Almohanna

Affiliations:

Dermatology and dermatologic surgery department,

Prince Sultan Military Medical City

Makkah Al Mukarramah Rd, As Sulimaniyah

Riyadh 12233, Saudi Arabia

Corresponding author:

Fares Abdulmajed Alkhayal, MD

Dermatologist

Prince Sultan Military Medical City

Riyadh 12233 (Saudi Arabia)

falkhayal@outlook.com

Abstract

Graham-Little Piccardi Lassueur Syndrome (GLPLS) is a rare variant of Lichen planopilaris (LPP) which characterized by triad of fibrosing alopecia of the scalp, non-fibrosing alopecia of the axilla and groin, and a follicular spinous papule over the body. LPP is a rare follicular subtype of lichen planus which causes scarring alopecia of scalp and there are three clinical subtypes of LPP including classic lichen planopilaris, frontal fibrosing alopecia and GLPLS. Herein we describe an adult dark-skinned Saudi male with GLPLS who has numerous body follicular papules, complete loss of axillary hair and partial loss of groin hair in addition to patchy fibrosing alopecia of the scalp. To the best of our knowledge, this is the first reported case of GLPLS in Saudi Arabia.

Introduction 
Graham-Little Piccardi Lassueur Syndrome (GLPLS) is a rare variant of lichen planopilaris (LPP) characterized by the triad of patchy scarring alopecia of the scalp, non-scarring alopecia of the axilla and groin, and a numerous follicular keratotic papules over the body ${ }^{1}$. It is more common in old age and in postmenopausal females, with only a very few reported cases in the literature wherein the disease has affected males in younger age. ${ }^{2}$ In our case, we report a young male who presented with features of cicatricial alopecia of the scalp, non-cicatricial alopecia of the pubic region and axilla, and a follicular spinous papule over the body.

\section{Case Report}

A 26-year-old healthy dark-skinned male presented to our dermatology department complaining of severe pruritus all over body including the scalp for more than 3 years and progressive hair loss. Family history was negative for a similar condition. On examination, the patient's skin was xerotic with ichthyosiform scales over the extremities and numerous follicular papules all over the body (figure 1). There was diffuse scarring alopecia involving the scalp (figure $2 \mathrm{~A}$ ). Moreover, there were patchy alopecia involving the eyebrows, beard and limbs hairs. The axillary hairs were lost (figure 3 ) and there was patchy alopecia with follicular papules involving pubic hairs (figure 4). Trichoscopic examination showed peripilar casts over the scalp (figure 2 B), eyebrows, beard, limbs hairs and loss of follicular openings over scalp. Skin biopsy was taken form follicular papule over right leg showed orthokeratosis, hypergranulosis, acanthosis and lichenoid infiltrate with necrotic keratinocytes (figure 5). Based on the clinical and histopathological features, a diagnosis of (GLPLS) was made.

\section{Discussion}

$G$ raham-Little-Piccardi-Lassueur syndrome GLPLS was first described by Piccardi in 1913. A second case was then described by Graham-Little in 1915 in a patient referred by Lassueur, resulting in the name it bears today ${ }^{3}$. Around 50 cases of GLPLS have been reported since then ${ }^{4}$. The condition presents most commonly in middle-aged white women and is characterized by a triad of cicatricial alopecia of the scalp, nonscarring alopecia of the axillae and/or groin, and a follicular papule over body. Its cause remains unknown, but more likely is a T-cell mediated autoimmune condition ${ }^{4}$. Recent studies showed that there is decrease expression of peroxisome proliferator-activated receptor (PPAR) and many patients respond well to PPAR $\gamma$ agonists 5. also, interferon and JAK singling is upregulated in $\mathrm{LPP}^{6}$.

The goal of treatment in GLPLS as well as in other scarring alopecia is to prevent progression of hair loss thus early diagnosis and intervention is crucial ${ }^{1}$. Many treatment modalities have been used in treating lichen planopilaris with variable results. Treatment options range from topical and intralesional steroid to systemic treatment such as hydroxychloroquine, cyclosporine and pioglitazone ${ }^{7}$. Baibergenova and Walsh ${ }^{8}$ used PPAR $\gamma$ agonists (Pioglitazone) which induced complete remission in $25 \%$ and significantly improved symptoms in $50 \%$ of patient diagnosed to have LPP. Pioglitazone side effects are very mild including calf pain, lightheadedness, nausea, dizziness, and hives which were experienced by less than $5 \%$ of patients ${ }^{8}$. Chiang et al ${ }^{9}$ studied the use of hydroxychloroquine in the treatment of LPP in 40 patients for twelve months. Their results showed that hydroxychloroquine was very effective in terms of controlling symptoms and halting disease progression with a $69 \%$ and $83 \%$ significant reduction in severity of LPP at both 6 and 12 months respectively. Treatment with oral tofacitinib either as monotherapy or as adjuvant to other treatment showed measurable $80 \%$ improvement clinically ${ }^{6}$ Excimer laser(308-nm) was used by Navarini et al twice weekly in 13 patients and all patient experienced relief of pruritus with $40 \%$ reduction in inflammation but only $25 \%$ of patients had hair regrowth ${ }^{10}$. Finally, naltrexone was used and showed improvement mainly in term of relieving symptoms such as pruritus ${ }^{11}$. Our patient was started on hydroxychloroquine after he was evaluated by ophthalmology and there was no contraindication to start the medication. In addition, the patient was started on topical treatment in the form of tretinoin $0.05 \%$ cream targeting follicular keratotic papules. On follow up, the patient reported improvement in term of pruritis and reduction on the severity of follicular keratotic papules.

\section{Conclusion}

GLPLS is a rare variant of LPP characterized by the triad of patchy fibrosing alopecia of the scalp, non- 
fibrosing alopecia of the axilla and groin, and a follicular spinous papule on the body. The exact cause still unknown and the goal of treatment is to stop disease progression and to reduce associated symptoms.

\section{Author Contributions}

Dr.Alkhayal was first one to examine the patient and doing biopsy and he wrote the introduction and abstract. Dr.Hind took the photo with dermtascope and 1 did Literature review plus auditing the case. dr almubark \& alsudairy wrote the conclusion and review the case.

key clinical message

This article Reviewed dermoscopic and pathological features of GLPLS. In addition to reviewing current and emerging treatment of GLPLS.

References:

1-Assouly P, Reygagne P. Lichen planopilaris: update on diagnosis and treatment. InSeminars in cutaneous medicine and surgery 2009 Mar 31 (Vol. 28, No. 1, pp. 3-10). No longer published by Elsevier.

2- Soares VC, Mulinari-Brenner F, Souza TE. Lichen planopilaris epidemiology: a retrospective study of 80 cases. Anais brasileiros de dermatologia. 2015 Oct;90(5):666-70.

3- Divine J, Rudnick EW, Lien M. Graham-Little-Piccardi-Lassueur syndrome. Cutis. 2019 May;103(5):E811.

4- Ghafoor R, Khoso BK, Anwar MI, Hashmi SF. Graham-Little-Piccardi-Lassueur syndrome: a rare case report and review of literature. Journal of Pakistan Association of Dermatology. 2016 Nov 26;25(4):327-30.

5- Karnik P, Tekeste Z, McCormick TS, Gilliam AC, Price VH, Cooper KD, Mirmirani P. Hair follicle stem cell-specific PPAR $\gamma$ deletion causes scarring alopecia. Journal of Investigative Dermatology. 2009 May 1;129(5):1243-57.

6- Yang CC, Khanna T, Sallee B, Christiano AM, Bordone LA. Tofacitinib for the treatment of lichen planopilaris: a case series. Dermatologic therapy. 2018 Nov;31(6):e12656.

7- Rácz E, Gho C, Moorman PW, Noordhoek Hegt V, Neumann HA. Treatment of frontal fibrosing alopecia and lichen planopilaris: a systematic review. Journal of the European Academy of Dermatology and Venereology. 2013 Dec;27(12):1461-70.

8- Baibergenova A, Walsh S. Use of pioglitazone in patients with lichen planopilaris. Journal of cutaneous medicine and surgery. 2012 Mar;16(2):97-100.

9- Chiang C, Sah D, Cho BK, Ochoa BE, Price VH. Hydroxychloroquine and lichen planopilaris: efficacy and introduction of Lichen Planopilaris Activity Index scoring system. Journal of the American Academy of Dermatology. 2010 Mar 1;62(3):387-92.

10- Navarini AA, Kolios AG, Prinz-Vavricka BM, Haug S. Low-dose excimer 308-nm laser for treatment of lichen planopilaris. Archives of dermatology. 2011 Nov 1;147(11):1325-6.

11- Strazzulla LC, Avila L, Lo SK, Shapiro J. Novel treatment using low-dose naltrexone for lichen planopilaris. Journal of drugs in dermatology: JDD. 2017 Nov 1;16(11):1140.

\section{Hosted file}

FIG.pdf available at https://authorea.com/users/425205/articles/530072-graham-littlepiccardi-lassueur-syndrome-and-review-of-the-literature 